\title{
Bio-Piracy on the High Seas? Benefit Sharing from Marine Genetic Resource Exploitation in Areas beyond National Jurisdiction
}

\author{
John Samuel Bird \\ Faculty of Law, University of New Brunswick, Fredericton, NB, Canada \\ Email: john@burkelaw.ca
}

How to cite this paper: Bird, J.S. (2018) Bio-Piracy on the High Seas? Benefit Sharing from Marine Genetic Resource Exploitation in Areas beyond National Jurisdiction. Natural Resources, 9, 413-428.

https://doi.org/10.4236/nr.2018.912026

Received: June 22, 2018

Accepted: December 26, 2018

Published: December 29, 2018

Copyright $\odot 2018$ by author and Scientific Research Publishing Inc. This work is licensed under the Creative Commons Attribution International License (CC BY 4.0).

http://creativecommons.org/licenses/by/4.0/

c) (i) Open Access

\begin{abstract}
Transnational benefit sharing from the exploitation of Marine Genetic Resources' (MGR's) in Areas Beyond National Jurisdiction (ABNJ) presents a unique problem in international law. Proposals to govern MGR's in ABNJ include leaving them unregulated, governance under the International Seabed Authority (ISA) or the Convention on Biological Diversity (CBD) or implementing a new international regime. This paper demonstrates that a hybrid solution for MGR governance under the ISA which is modeled on the CBD and The Nagoya Protocol (Nagoya), provides the most adroit solution to the problem of equal benefit and access to MGR's for all States. This solution ensures adequate conservation of MGR's, meanwhile fostering sustainable exploitation and maintaining equality in access, biodiversity and the sharing of financial and technological benefits amongst the international community. Further, examining benefit sharing from bioprospecting under the $\mathrm{CBD}$ and Nagoya provides a foundation for a benefit-sharing regime in ABNJ under The United Nations Convention on the Law of the Sea (UNCLOS). Examining the CBD, Nagoya and UNCLOS demonstrates how benefits arising from exploitation of MGR's in the high seas and deep bed should be included as a mandate of the ISA. This methodology is accomplished by focusing on bioprospecting for MGR's and how the CBD and Nagoya facilitate access to the resource while ensuring that the host State or community benefits from granting access. As the CBD and Nagoya focus on benefit sharing in light of national sovereignty, and UNCLOS regulates in areas beyond national jurisdiction, the ISA is perfectly placed to adopt the principles of the CBD and Nagoya and provide a mechanism to ensure that MGR's in ABNJ are adequately conserved and the benefits arising from their exploitation equitably shared.
\end{abstract}




\section{Keywords}

Marine Genetic Resources, Natural Resources, Biodiversity, Bioprospecting, International Seabed Authority, Nagoya Protocol, Convention on

Biodiversity, Law, Conservation, Benefit Sharing, High Seas,

Deepsea Bed, Area

\section{Introduction}

Approximately 1.75 million species of plants, animals and microorganisms have been identified on Earth, with scientific estimates placing the actual number between 13 million and 100 million [1]. The genetic diversity among these species coupled with their interactions within unique ecosystems compromises what is known as biodiversity [1]. Biodiversity sustains both human life and a vast portion of the global economy [2]. The immense potential supported by biodiversity, and the prospect of increased benefits have resulted in a loss of global biodiversity, one of the most pressing international environmental problems [3]. Clearly, the Earths abundant biodiversity needs no introduction, yet the myriad of benefits that biodiversity provides [1] carries with it a plethora of issues and challenges ranging from conservation to equitable benefit sharing from exploitation. The problem of equity arises primarily as a result of the regional imbalance in biodiversity between the developed and developing nations [4].

The developed States, many of which are biodiversity poor, have long benefitted from accessing and exploiting the rich biodiversity of developing States [4]. The problem is magnified when exploitation occurs in maritime areas beyond national jurisdiction (ABNJ). As technology increases, the ability for developed States to exploit the deep-sea bed [5] (known as the Area) to derive benefits from marine genetic resources (MGR's) has also increased. In this region, known as "the common heritage of mankind" [6], the imbalance between developed and developing States accessing and deriving benefits from MGR's is apparent.

The divide between developed and developing countries accessing, exploiting (bioprospecting) and receiving benefits from MGR's in ABNJ is amplified due to a gap in legislation governing exploitation of MGR's in the high seas and the Area [7]. Regarding benefit sharing, international law only provides for benefit sharing from mineral exploitation in the Area and not for living resources [7]. However, the international community has adopted four instruments that provide guidance on how to appropriate the benefits associated with bioprospecting for MGR's in ABNJ.

The four instruments that will be examined are The Convention on Biological Diversity (CBD), The Nagoya Protocol (Nagoya), The United Nations Convention on the Law of the Sea (UNCLOS) and the Agreement Relating to the Implementation of Part XI on the United Nations Convention on the Law of the Sea (Part XI). These instruments have sought in part to either halt the impact of 
human activities on biodiversity [3] or redress the imbalance between the benefits gained from exploitation [8] in areas of national sovereignty or the international commons. Examining these agreements in light of benefit sharing and the conservation of biodiversity, demonstrates the need for a legal regime to foster benefit sharing of MGR's in ABNJ and the challenges associated with their exploitation.

The CBD and Nagoya pertain to biodiversity loss within areas of national sovereignty, establishing a mechanism that facilitates access to biodiversity whilst ensuring that the providers receive a share in the benefits from exploitation [9]. Through UNCLOS, the international community has created a legal regime applicable to maritime areas outside of sovereignty claims in the high seas and the Area [6]. UNCLOS however is silent on bioprospecting for MGR's in these areas. Silence on this issue has not only created a gap in legislation but an imbalance between States able to benefit from access to MGR's and those without the capability to do likewise.

This paper will examine these four international agreements and demonstrate how benefits arising from exploitation of MGR's in the high seas and the Area should be included as a mandate of the International Seabed Authority (ISA). This can be accomplished by focusing on bioprospecting for MGR's and how the CBD and Nagoya facilitate access to the resource while ensuring that the State or the community benefits from granting access. Further, examining benefit sharing from bioprospecting under the $\mathrm{CBD}$ and Nagoya provides a foundation for a benefit-sharing regime in $\mathrm{ABNJ}$ under UNCLOS.

\section{Bioprospecting for Biodiversity}

The CBD has defined genetic material as including "any material of plant, animal, microbial or other origin containing functional units of heredity" and having "actual or potential value" [10]. Bioprospecting is defined by the United Nations Development Program as "the systematic search for biochemical and genetic information in nature in order to develop commercially-valuable products for pharmaceutical, agricultural, cosmetic and other applications. The rationale is to extract the maximum commercial value from genetic resources and indigenous knowledge, while creating a fair compensation system that can benefit all. The phases of bioprospecting start with sample collection, isolation, characterization and move to product development and commercialization. Bioprospecting is possible both in terrestrial and marine environments." [11].

Bioprospecting for genetic resources has led to developments in multiple fields, from biology and chemistry to IT and industry [2]. Information gained from local communities as a result of bioprospecting has made a significant impact on research and development especially in the pharmaceutical and agricultural sectors [12]. Bioprospecting for example, may involve the discovery of a new species of plant, which because of its unique characteristics could be used in the development of a pharmaceutical drug [13]. The bioprospecting industry is 
worth between $\$ 17.5$ and \$30 million USD [2] and one study estimates that as much as $\$ 800$ billion USD of the global community is based on products derived from bioprospecting [2].

The divide between biodiversity rich developing nations and biodiversity poor developed countries (though there are of course exceptions) has created a regional imbalance in equity and fairness in terms of the benefits derived from exploiting these resources [4]. The regional imbalance between access to and the sharing of benefits derived from bioprospecting has resulted in a problem that calls for an acute international solution [13]. However, there are many conflicting policy aims that challenge designing an international solution to this problem, such as development, commercial interests and scientific research [13].

Further, bioprospecting (as well as the conservation of biodiversity) is carried out, not by governments, but by private entities such as pharmaceutical companies, research agencies and conservation institutes [13]. Oftentimes, the information gained is not from the government of the country they are seeking access too, but through local and indigenous communities who provide the information on the uses of the resource [13]. The CBD and its offspring Nagoya seek to address global biodiversity loss as well as foster access and benefit sharing (ABS) between States, communities and other agencies that have competing interests [10] [14].

\section{Access and Benefit Sharing under the CBD and Nagoya}

Until the implementation of the CBD, biological resources were regarded as the common heritage of mankind in areas of national sovereignty [15]. Regarding biodiversity as the common heritage of mankind resulted in resource exploitation, which was taken and transported freely and unconditionally across national borders [16]. The same problem still exists today with MGR's located in the Area and the high seas.

Biodiversity was in effect stolen [15], and States abundant in resources were unable to benefit from its exploitation by other States [15]. The exploration and subsequent exploitation of genetic resources become known as bioprospecting [15]. Various agencies were able to bioprospect for agricultural and pharmaceutical purposes and began to "take advantage of the genetic resources and traditional knowledge that exist in developing countries" [15]. However, after the adoption of the CBD a different approach was implemented [15] and States were given sovereignty over biodiversity and the benefits it provided.

The CBD is a child of the 1992 United Nations Conference on Environment and Development in Rio de Janiero, Brazil (Rio) [15]. As part of its mandate, the CBD seeks to conserve global diversity and to ensure fairness, equity and justice with respect to benefits derived from genetic resources [15]. The CBD entered into force in 1993 [13] and currently 196States are party to the convention with 168 being signatories [17]. Almost twenty yearly later, Nagoya was adopted in October 2010 in Nagoya, Japan currently with 92 signatories [18] (it will not en- 
ter into force until the fiftieth State ratifies it) [8]. Nagoya "significantly expands and fleshes out the general framework on access and benefit sharing" established by the CBD [9].

Under the $\mathrm{CBD}$, there are two separate approaches to benefit sharing: interstate benefit sharing and one centered on local communities or indigenous groups [9]. The relevant portions of the CBD state:

" $8(\mathrm{j})$ Each Contracting Party shall, as far as possible and as appropriate subject to its national legislation, respect, preserve and maintain knowledge, innovations and practices of indigenous and local communities embodying traditional lifestyles relevant for the conservation and sustainable use of biological diversity; [10] 15(2) Each Contracting Party shall endeavour to create conditions to facilitate access to genetic resources for environmentally sound uses by other Contracting Parties, and 15(7) Each Contracting Party shall take legislative, administrative or policy measures... with the aim of sharing in a fair and equitable way the results of research and development and the benefits arising from the commercial and other utilization of genetic resources with the Contracting Party providing such resources" [10].

Though both provisions of the $\mathrm{CBD}$ require benefit sharing, they are in essence conceptually different [9]. Article 8 applies to information and knowledge whereas Article 15 applies to physical properties [9].

Nagoya builds on the ABS provisions of the CBD by requiring countries providing the resources or traditional knowledge to adopt national mechanisms that facilitate access [3]. According to Nagoya, an access State should adopt national legislation that uses a certificate which provides information on: the issuing authority, the date, the provider, to whom prior informed consent was granted, the subject-matter or genetic resources covered and confirmation that mutually agreed terms were reached, and that consent was obtained [3] [13]. The certificates act as tracking systems that help to facilitate national approval mechanisms and to ensure that no illegal use is made of the resource [3] [14]. Ensuring appropriate use is accomplished through established checkpoints in customs, patents, product authorities, research funding organizations and scientific journals [3] [14].

However, the effectiveness of the benefits sharing regime under Nagoya has been challenged on multiple platforms. Developing nations have expressed that Nagoya fails to make compliance mechanisms mandatory [3] [14]. Further, the success of the access and benefits regime requires widespread implementation, but implementation is performed on a State-by-State basis [3] [14]. Conversely, entities such as research institutes and private companies in developed States have argued that access to genetic resources is being restricted by developing countries [3] [14]. From another perspective, it can be argued that benefit sharing under the CBD and Nagoya is unsuccessful because biodiversity continues to decline [19].

It is important to note that while the CBD is aimed at reducing global biodi- 
versity, the provisions on benefit sharing are focused on guaranteeing fairness to the host countries whilst ensuring access is granted on a sustainable basis. If the CBD and Nagoya are examined under this light, there is a strong argument that they have been successful. Primarily, as has already been mentioned, the CBD hailed the end of the idea that biodiversity is common property. No longer were the resources provided for by biodiversity free for exploitation by all states and enterprises regardless of territorial boundaries. The CBD and Nagoya have ensured that resource exploitation in developing States occurs with the caveat that the host State/community must in some form benefit from granting access to the resource or from providing knowledge.

Applying the idea of sovereignty to biodiversity transferred the rights from the exploiters to the providers [3]. Ensuring that host countries had sovereignty over their resources gave them both authority and autonomy over decisions regarding their exploitation [3]. Further, it ensures that the host country receives an economic incentive from allowing access to national resources [3]. Therefore, sovereignty as opposed to the common heritage of mankind, allows host States to have the ability to manage (and so conserve) biodiversity within national boundaries as well as to facilitate the potential for economic gain [3]. Conservation coupled with economic gain in developing States can foster social and economic growth [3]; a benefit that is a direct result of the sharing provisions in the CBD and Nagoya.

The benefits sharing provisions within the $\mathrm{CBD}$ and Nagoya allow developing States to conserve their biodiversity in a manner that promotes economic, social and environmental accountability for all involved in the exploitation. However, UNCLOS has opposed the sovereignty approach and has opened the international commons in the high seas as "free for all States" [6] and the Area as the "common heritage of mankind" [6].

\section{MGR's and Why Benefit Sharing Is Necessary}

As the surface of planet Earth is $70 \%$ water, the oceans provide incredible biodiversity and contain richness in speciation of flora, fauna and minerals that may outnumber those found terrestrially [20]. The high seas and the Area were once thought to be void of life, given the seemingly inhospitable environment the high pressure, low temperature and absence of sunlight has created [7]. Further, the harsh conditions associated with hydrothermal vents as a result of their acidity and boiling temperatures were also once thought of as too harsh to sustain life [7].

Rather than creating ecosystems in which life is impossible to flourish, these aquatic conditions have fostered a world in which biodiversity has prospered [7]. Many of the ecosystems associated with the high seas and the Area such as hydrothermal vents, cold water reefs and cold seeps support unique organisms that have drawn the attention of both the scientific [21] and commercial communities [22]. MGR's in these areas include microorganisms, bacteria, animals, plants 
and seaweeds whose environments not only separate them from any similarity to terrestrial species but also have caused them to evolve and contain properties capable of withstanding harsh conditions [23]. The unique properties of MGR's in the high seas and the Area have made them highly significant for research and development [23].

The benefits associated with bioprospecting for MGR's has resulted in increased exploitation by States and enterprises [22]. So far, bioprospecting for marine organisms has resulted in the production of more than 18,000 natural products from approximately 4800 species [24]. Resources derived from marine organisms are used in products in areas as diverse as aquaculture, food, cosmetics, industry, ecotoxology, bioremediation and bio-fuel production [24]. The bulk of bioprospecting in ABNJ has occurred within the last decade with more than $95 \%$ of patents claimed involving marine resources filed after the year 2000 [23]. Further as of 2009, more than 15,000 molecules have been identified leading to 677 patents with additional patents arising from products made from resources derived from the deep sea [23]. 90\% of these patents have been made by only 31 countries, with $70 \%$ made by the USA, Germany and Japan alone [23].

The discrepancy between the 31 States with patent claims and the other 165 sovereign States can be largely attributed to technology and economics [23], highlighting the interstate discrepancy in accessing and benefiting from MGR's. Exploring in these areas requires both advanced technology and financial capital and are therefore only open to a few States [23]. Thus, a monopoly in the exploitation of MGR's has resulted between the developed over the developing States [23]. This monopoly harkens back to the approach taken to terrestrial resources before the advent of the CBD.

The challenge has become, that as ABNJ are free from any notion of sovereignty, how does UNCLOS ensure MGR's in these areas are exploited in a manner that ensures equity and fairness from benefits derived from their exploitation. As of yet, the international community has failed to solve this problem. However, UNCLOS does provide some guidance and challenges on how MGR's should be exploited in a manner that ensures equitable benefits sharing.

\section{MGR's under UNCLOS and the Challenge of Benefit Sharing}

The international community adopted UNCLOS on the $16^{\text {th }}$ of December 1982 , which came into force almost fourteen years later on the $16^{\text {th }}$ of November 1996 [25]. As of the $3^{\text {rd }}$ of April 2018, there were 168 State parties to UNCLOS with Azerbaijan being the latest country to accede to the agreement on 16 June 2016 [26]. The purpose of UNCLOS was to devise an international legal regime that would encompass every aspect of governance on the seas [25]. This goal has largely been accomplished as UNCLOS covers almost all areas of maritime regulation, including: maritime boundary limits, navigation, conservation of biodiversity, access, research and dispute settlement. 
UNCLOS has been described as "the major international legal delimitation of private property on planet Earth" [20]. UNCLOS delimits maritime boundaries into a series of regressing zones of jurisdiction. Coastal States enjoy full sovereignty over the sea, seabed, subsoil and airspace over an area known as the territorial sea, [6] which extends 12 nautical miles $(\mathrm{nm})$ as measured their coastal baselines [6]. The next zone is known as the exclusive economic zone (EEZ) and measures $200 \mathrm{~nm}$ from the coastal baseline [6]. In the EEZ, States are given sovereign rights to explore, exploit, manage and conserve the natural resources in the water column, the seabed and the subsoil [6]. The third maritime zone pertains to the continental shelf, which under UNCLOS is the seabed and subsoil along the continental rise that extends from the territorial sea to the end of the EEZ, but does not include the deep ocean floor [6]. States claiming a continental shelf do not have any rights to the super adjacent water column [6].

The fourth area is known as the high seas, which begin at the $200 \mathrm{~nm}$ EEZ [6] and are open to all States, [6] with the caveats that they must be reserved for peaceful purposes [6] and are subject to the interests of other States [6]. The final zone is known as the Area and is comprised of the seabed, ocean floor and subsoil in areas beyond national jurisdiction [6]. As the CBD encapsulates areas of national sovereignty, this section will focus on the marine zones, not under the umbrella of the benefit sharing provisions in the CBD or Nagoya. Rather this discussion will focus on the areas outside of national jurisdiction, particularly the high seas and the Area.

The Area has been designated as the common heritage of mankind [6] and therefore the resources contained therein are outside of any claims of national sovereignty or sovereignty rights [6]. In the high seas, all States are guaranteed the freedom of universal access [6], therefore obtaining access or gaining permission to the MGR's in the high seas is not an issue under UNCLOS. Furthermore, UNCLOS guarantees all states the right to conduct scientific research in the high seas [6] and in the Area [6], so long as they are done so for peaceful purposes and take into account environmental stewardship [6]. UNCLOS does not however, focus on benefits sharing of genetic resources derived from areas beyond national jurisdiction [7]. Excluding governance of MGR's in ABNJ has resulted in a gap in legislation. Currently, there are no mechanisms under UNCLOS pertaining to managing the exploitation of or the benefits derived there from of MGR's in the high seas and the Area.

Articles 144 and 244 are two of the provisions in UNCLOS that contain an element of benefit sharing similar to Nagoya and the CBD. Article 144 relates to research undertaken in the Area and states,

"1) The [ISA] shall take measures in accordance with this Convention: a) to acquire technology and scientific knowledge relating to activities in the Area; and b) to promote and encourage the transfer to developing States of such technology and scientific knowledge so that all States Parties benefit therefrom, and 2) To this end the [ISA] and States Parties shall cooperate in promoting the 
transfer of technology and scientific knowledge relating to activities in the Area so that the Enterprise and all States Parties may benefit therefrom." [27]

The other provision, Article 244, relates to research in ocean in zones other than the Area, stating in part,

“2) For this purpose, States, both individually and in cooperation with other States and with competent international organizations, shall actively promote the flow of scientific data and information and the transfer of knowledge resulting from marine scientific research, especially to developing States, as well as the strengthening of the autonomous marine scientific research capabilities of developing States." [27]

Under UNCLOS, any research activities carried out in either the high seas or the Area cannot be used as mechanisms to claim ownership over any part of the marine environment or its resources [6] [28]. However, UNCLOS is silent on the state of any proprietary rights that are associated with the scientific research [7]. UNCLOS is also silent on the definition of "marine scientific research" which gives uncertainty as to whether research involves solely academic purpose or if it extends to research for commercial purposes as well [21] i.e. pharmaceuticals. It has been argued that since there is not a division between researching for academic or commercial purposes, any research conducted must be undertaken in accordance with Article 143 of UNCLOS [23].

Article 143 also includes elements of benefit sharing such as cooperation and sharing of results, [27] which is governed by the International Seabed Authority (ISA). Apart from research, the exploring for and the subsequent exploitation of resources found in the Area are also governed by the ISA [29]. However, neither researching nor bioprospecting for genetic resources found in the Area is stated as a mandate of the ISA [29]. As a result, genetic resources located in the Area are often argued as falling within the high seas regime, which means that they are open for exploitation save for the interests of other States [29].

However, UNCLOS is explicit on the requirement to transfer scientific knowledge and technology from States researching in the Area [27] with those that cannot. Technology sharing is essential because by sharing the technology required to exploit resources belonging to mankind with other States, it ensures fair access in the future and therefore equitable benefits [20]. Further, by sharing technology with States unable to access MGR's means that all States have the opportunity not only to exploit resources in these areas but also the ability to aid in their conservation [20]. However as previously mentioned, the provisions regarding benefit sharing in the Area only apply to mineral resources and not natural ones.

Though bioprospecting for MGR's in areas beyond national jurisdiction falls within UNCLOS [30], it is hard to determine how UNCLOS facilitates their exploitation in a way that benefits mankind as a whole. However, it is clear that the present regime presents several challenges for the implementation of benefit sharing from scientific and or economic exploitation of marine genetic re- 
sources.

I have identified what I believe to be the three most significant challenges inhibiting the implementation of benefits sharing for MGR exploitation under UNCLOS. The first challenge relates to the inability to distinguish between which UNCLOS regime applies to MGR's (the Area or the High Seas). The second challenge is the lack of mechanisms under UNCLOS to ensure that monetary, scientific and technological benefits from exploitation of MGR's in the high seas and the Area are shared. The final challenge relates to the loss of biodiversity resulting from the deficiency in concrete legal regulations for MGR's in ABNJ. These problems will be discussed before a solution to the challenge of ensuring equitable benefit sharing of MGR's in areas beyond national jurisdiction is presented.

Perhaps the major flaw associated with MGR governance under UNCLOS is that two regimes potentially apply to benefit sharing from exploitation in ABNJ. As MGR's are found in both the water column of the high seas [6] and the Area [6], two systems of governance may apply to their exploitation. However, to ensure equitable benefit sharing, one system under UNCLOS is needed. Currently, the water column is subject to the "freedom of the high seas" [6] and the Area is governed by the "common heritage of mankind" [6] principle, both of which have different consequences for benefits sharing from MGR exploitation [28]. As a result, on the high seas, there is access to genetic resources but no requirement to share the benefits derived from the access; in the Area, there is a requirement to ensure that scientific research is for the benefit of all [28].

The division between these two schemes opens the door for States, with the capability of MGR exploitation, to conduct research for either academic or commercial purposes in the high seas without having to share the benefits of exploiting a common resource with others. Further issues arise as UNCLOS refers to resources in the Area as mineral resources [27] rather than genetic, therefore the common heritage principle (and so technology and scientific transfers mandates) may not apply to them even if they are found in the Area [21]. Exploiting States can use this differentiation to argue that exploiting MGR's in the Area does not require them to share technological or scientific benefits.

This issue is magnified given the nature of MGR's. For example, "how does one determine in which of the two regimes a microbe living in symbiosis with the local fauna falls, or perhaps a microbe found in the proximity of a thermal vent" [23]. Therefore, there are two different regimes applicable to resources, which because of their lifecycle and nature may belong to both. Under UNCLOS, the result is that in areas beyond national jurisdiction, exploitation of MGR's may only be subject to the general duty of States to "conserve and manage marine living resources set forth in UNCLOS Article 117" [21] rather than to share any form of scientific, technological or monetary benefits.

Another flaw under UNCLOS is that the benefit sharing provisions are weak and may not apply to MGR's. Though regulated under UNCLOS, technology 
sharing is not mandatory under Part XI [20]. The result of non-mandatory technology sharing has resulted in the capability of only a few States to access and exploit MGR's in ABNJ [28]. The consequence of non-binding technology transfer requirements has been that poor and developing States only have access to approximately $46 \%$ of the world's surface and are unable to engage in either the exploitation or conservation of MGR's in the Area [20]. Even though the provisions on technology sharing are wanting, they are still mandated under UNCLOS, which however, contains no provisions to ensure that monetary, technological or scientific benefits flowing from MGR exploitation in the high seas are shared [7].

One of the reasons why benefit sharing from MGR exploitation is inadequately governed under UNCLOS concerns our understanding of their biology. MGR's are neither minerals nor are they currently a benchmark for biodiversity and therefore do not easily fit within any given regime under UNCLOS [7]. The inability to place MGR's within a category currently covered by UNCLOS has resulted in political deadlock between developed and developing countries. Developing countries push for including MGR's as part of the common heritage mankind from stating the benefits must be shared equally [29]. On the other hand, developed countries argue that the exploitation and conservation of MGR's in the deep seas currently falls outside of the scope of UNCLOS, stating that an additional, not yet envisioned arrangement, must apply to them in the future [29].

However, as microorganisms, MGR's are living resources and so fall UNCLOS's mandate that all active States must conserve and manage living resources in ABNJ [21]. Under UNCLOS, management and conservation efforts however have focused on fisheries and marine mammals rather than on MGR's [21]. Nevertheless, as bioprospecting increases and the uses of MGR's in a variety of industries are increased as well, the need for appropriate conservation measures is becoming more apparent [22]. Further as it is uncertain whether MGR's fall within the common heritage regime or the freedom of the high seas, their exploitation must certainly fall within the general duty of States to conserve and manage resources in areas beyond national jurisdiction [6].

The difficulty with conserving MGR's in these areas is magnified and exemplified by microorganisms. Conservation measures to protect eukaryotic species are scant and for prokaryotics, conservation efforts are non-existent, both of which may constitute MGR's [24]. To date, sufficient ecological data from only 36 of the 340 eukaryotic species used in patents exists [24]. Of these 36 species, the Red List of Endangered Species of the International Union for Conservation lists two as endangered, six as vulnerable and seven as near threatened [24]. Therefore, of the data provided for 36 microorganisms exploited as MGR's, almost half are in a state of decline. Clearly, this is a significant issue for both maritime conservation and global biodiversity, which is currently without a concrete regime to address it. 
One author has suggested that since MGR's are not directly a part of the common heritage model under UNCLOS, their exploitation in areas beyond nation jurisdiction must constitute a common concern of mankind [23]. If MGR's are a common concern of the international community, their exploitation should only occur if it is in line with the relevant portions of the CBD: prior informed consent and the fair and equitable sharing go the benefits arising from their exploitation [23]. A solution for the sharing of benefits derived from MGR's in the high seas and the Area, must take into account the need for equity amongst States with and without the capacity for exploitation. This solution must also consider and regulate exploitation of MGR's in a manner that promotes conservation of biodiversity and environmental stewardship.

\section{A Solution}

Petra Drankier and her colleagues have argued that there are four possible solutions to governing MGR's in ABNJ. These solutions would ensure that benefits arising from MGR exploitation are equitably shared. Drankier's solutions include leaving MGR's unregulated, bringing them within the ISA, governing them under the CBD or and implementing a new international regime [28].

I believe that a hybrid solution of the ISA and the CBD would work best. This hybrid solution would bring MGR's within the mandate of the ISA to ensure adequate conservation and to foster exploitation, carrying with it the caveats established in the CBD and Nagoya to ensure equality in access, biodiversity conservation and the sharing of benefits.

The primary mandates of the ISA are to regulate mining in the deep seabed and the conservation and management of the environment in light of exploration and exploitation of its natural resources [31]. As the CBD also seeks to promote conservation of the natural environment, MGR's should be brought within this mandate. Although the ISA does not regulate activities relating to bioprospecting for MGR's, their mandate should be expanded to include their exploration and exploitation in the Area as well as the water column of the high seas.

The ISA has largely succeeded in its goals to reserve the Area for peaceful purposes and to implement a system that governs the exploitation of the Area's mineral resources [32]. Success is evidenced in the universal acceptance of the ISA's authority [32]. As of 2012, the ISA has issued eleven exploration contracts, covering 770,000 square kilometers of the Area [32]. Mining has yet to occur in the Area and so monetary benefit sharing has not occurred [32]. However, there has been a rise in sharing of scientific research and conservation in the Area, both of which benefit the global community [32].

The ISA has fostered benefit sharing in the Area through initiatives which include: international workshops on scientific matters, technical studies on various issues, a geological model of the Clarion-Clipperton Zone and the Kaplan Project to study species range and biodiversity in the same region [32]. These in- 
itiatives have involved participation of scientists from developing States, which "will contribute to a much better understanding of the deep ocean environment for the benefit of future generations... [and form] the basis for the formulation of a comprehensive environmental management plan... as one of a suite of measures designed to ensure effective protection for the marine environment from harmful effects arising from deep seabed mining" [32]

Many of the activities occurring in the Area, such as seabed exploration, research and technology sharing are governed by the ISA [20]. Adding governance of MGR exploration, exploitation, research and technology would not be overly burdensome given the significant overlap between the two schemes. The necessary mechanisms to ensure benefits sharing are already established within the ISA and so expanding its mandate would be less cumbersome than designing and creating a new international agreement and body to facilitate these matters. In managing mineral resources, the ISA has gained invaluable experience and expertise that would be crucial to MGR governance in the same jurisdiction.

UNCLOS also demands that all activities occurring in areas beyond national jurisdiction are undertaken with environmental stewardship [6]; therefore compromising the natural environment in such areas is a gross violation of this international principle [20]. Further, as access in areas beyond national jurisdiction carries with it environmental caveats and so a form of accountability, [20] exploiting MGR's must also carry with it the requirement for environmental stewardship under this existing principle.

The ISA is perfectly positioned to ensure accountability, as it already regulates access, environmental stewardship and benefit sharing in the Area. It could be argued that MGR's in the water column should not be governed by the same principles as those in the Area. However, as the exact location of MGR's is uncertain, the international community should place the higher legal burned on those exploiting the resource rather than deprive the international community of benefits taken from exploitation in the global commons.

In addition, Part XI to UNCLOS was implemented in order to provide an "equitable and efficient utilization of sea resources [which will] contribute to the realization of a just and equitable international economic order which takes into account the interests and needs of mankind as a whole and in particular, the special interests and needs of developing countries" [29]. Ensuring that developing nations are provided with the scientific, technological and monetary benefits associated with exploiting MGR's will provide for a regime that is just, equitable and accounts for desires embedded within the CBD, Nagoya and UNCLOS.

As the CBD and Nagoya focus on benefit sharing in light of national sovereignty [28], and UNCLOS regulates in areas beyond national jurisdiction, the ISA is perfectly placed to adopt the principles of the CBD and Nagoya and provide a mechanism to ensure that MGR's in ABNJ are adequately conserved and the benefits arising from their exploitation equitably shared. 


\section{Conclusions}

Benefits sharing from the exploitation of MGR's in ABNJ presents a unique problem in international environmental law. The CBD and Nagoya demand benefit sharing for resources found within national boundaries and UNCLOS and Part XI stipulate that resources in the Area and high seas are part of the global commons. As a result, the exploitation of MGR's in ABNJ is neither covered under the sovereignty approach adopted by the CBD and Nagoya, nor does it fall directly within any guidelines provided by UNCLOS on benefit sharing.

However, UNCLOS does demand that all activities in the high seas take into account environmental conservation and management and that the benefits from mineral resources exploited in the Area must be shared equitably. Using the principles from the CBD and the rules set out in UNCLOS, exploitation of MGR's in the global commons must take into account the need for fairness in sharing scientific, monetary and technological benefits. The ISA contains mechanisms to foster benefit sharing from mineral exploitation in the Area, providing an ideal framework for MGR exploitation and benefit sharing. Not only will this new regime ensure fairness amongst all States but it will also aid in the conservation of MGR's, whose brilliant biodiversity sets the cornerstone of much of the global social, economic and environmental foundations.

\section{Conflicts of Interest}

The author declares no conflicts of interest regarding the publication of this paper.

\section{References}

[1] Convention on Biological Diversity. (2013) Biodiversity-The Web of Life. http://www.cbd.int/convention/guide/default.shtml

[2] Afreen, S. and Abraham, B.P. (2009) Bioprospecting: Promoting and Regulating Access to Genetic Resources and Benefit Sharing. Decision, 36, 121-158.

[3] Carmen, R. (2011) Effective Governance of Access and Benefit Sharing under the Convention on Biological Diversity. Biodiversity Conservation, 20, 2243-2261. https://doi.org/10.1007/s10531-011-0086-0

[4] De Jonge, B. (2011) What Is Fair and Equitable Benefit-sharing? Journal of Agricultural \& Environmental Ethics, 24, 127-146. https://doi.org/10.1007/s10806-010-9249-3

[5] Russell, L. (2009) The Future of the Seabed. Economic Affairs, 29, 69-70. https://doi.org/10.1111/j.1468-0270.2009.01898.x

[6] Division for Ocean Affairs and the Law of the Sea, Office of Legal Affairs, United Nations (1982) United Nations Convention on the Law of the Sea.

[7] Schoenberg, P.L. (2009) Polarizing Dilemma: Accessing Potential Regulatory Gap-Filling Measures for Arctic and Antarctic Marine Genetic Resources Access and Benefit Sharing. Cornell International Law Journal, 42, 271-299.

[8] Warren, L.M. (2010) The Convention on Biological Diversity: Will the Decisions Made at Cop10 in Nagoya Make It Easier to Conserve Biodiversity? Environmental Law Review, 12, 245-255. https://doi.org/10.1350/enlr.2010.12.4.099 
[9] Buck, M. and Hamilton, C. (2011) The Nagoya Protocol on Access to Genetic Resources and the Fair and Equitable Sharing of Benefits Arising from Their Utilization to the Convention on Biological Diversity. Review of European Community \& International Environmental Law, 20, 47-61. https://doi.org/10.1111/j.1467-9388.2011.00703.x

[10] United Nations (1992) United Nations Convention on Biological Diversity.

[11] United Nations Development Programme (2016) Financing Solutions for Sustainable Development. Bioprospecting. 1-5.

http://www.undp.org/content/dam/sdfinance/doc/Bioprospecting\%20_\%20UNDP. pdf

[12] Torri, M.C. (2009) Beyond Benefit Sharing Agreements: Bioprospecting for the Poor? International Journal of Technology Management and Sustainable Development, 8, 103-127. https://doi.org/10.1386/ijtm.8.2.103/1

[13] Siebenhuner, B. and Suplie, J. (2005) Implementing the Access and Benefit-Sharing Provisions of the CBD: A Case for Institutional Learning. Ecological Economics, 53, 507-522. https://doi.org/10.1016/j.ecolecon.2004.10.012

[14] Secretariat of the Convention on Biological Diversity, United Nations (2010) The Nagoya Protocol on Access to Genetic Resources and the Fair and Equitable Sharing of Benefits Arising from Their Utilization to the Convention of Biodiversity.

[15] Smagadi, A. (2006) Analysis of the Objectives of the Convention on Biological Diversity: Their Interrelation and Implementation Guidance for Access and Benefit Sharing. Columbia Journal of Environmental Law, 16, 243-284.

[16] Morgera, E. and Tsioumani, E. (2010) The Evolution of Benefit Sharing: Linking Biodiversity and Community Livelihoods. Review of European Community \& International Environmental Law, 19, 150-173. https://doi.org/10.1111/j.1467-9388.2010.00674.x

[17] Convention on Biological Diversity (2013) List of Parties. http://www.cbd.int/convention/parties/list

[18] Convention on Biological Diversity (2013) Status of Signature, and Ratification, Acceptance, Approval or Accession. http://www.cbd.int/abs/nagoya-protocol/signatories/default.shtml

[19] Convention on Biological Diversity (2010) Global Biodiversity Outlook 3. http://www.cbd.int/gbo3/?pub=6667\&section=6711

[20] Thompson, C.B. (2004) International Law of the Sea/Seed: Public Domain versus Private Commodity. Natural Resources Journal, 44, 841-866.

[21] Beslier, S. (2009) The Protection and Sustainable Exploitation of Genetic Resources of the High Seas from the European Union's Perspective. The International Journal of Marine and Coastal Law, 24, 333-341. https://doi.org/10.1163/157180809X421725

[22] Ypsita, D. and Chugh, A. (2010) The Role of Traditional Knowledge in Marine Bioprospecting. Biodiversity Conservation, 19, 3015-3033. https://doi.org/10.1007/s10531-010-9879-9

[23] Bonfanti, A. and Trevisanut, S. (2012) TRIPS on the High Seas: Intellectual Property Rights on Maritime Genetic Resources. Brook Journal of International Law, 37, 187-232.

[24] Arrieta, J.M., et al. (2010) What Lies Underneath: Conserving the Oceans' Genetic Resources. Proceedings of the National Academy of Sciences of the United States of America, 107, 18318-18324. http://www.pnas.org/content/107/43/18318 
https://doi.org/10.1073/pnas.0911897107

[25] Food and Agriculture Organization of the United Nations, Fisheries and Aquaculture Department (2013) The United Nations Convention on the Law of the Sea. http://www.fao.org/fishery/topic/14839/en

[26] United Nations: Division for Ocean Affairs and the Law of the Sea (2013) Chronological Lists of Ratifications of, Accessions and Successions to the Convention and the Related Agreements as at 3 April 2018.

http://www.un.org/Depts/los/reference_files/chronological_lists_of_ratifications.ht $\underline{\mathrm{m}}$

[27] Division for Ocean Affairs and the Law of the Sea, Office of Legal Affairs, United Nations (1982) United Nations Convention on the Law of the Sea. Part XI.

[28] Drankier, P., et al. (2012) Marine Genetic Resources in Areas beyond National Jurisdiction: Access and Benefit Sharing. The International Journal of Marine and Coastal Law, 27, 375-433. https://doi.org/10.1163/157180812X637984

[29] Lehmann, F. (2007) The Legal Status of Genetic Resources of the Deep Seabed. New Zealand Journal of Environmental Law, 11, 33-66.

[30] Scovazzi, T. (2011) The Conservation and Sustainable Use of Marine Biodiversity, Including Genetic Resources in Areas Beyond National Jurisdiction: A Legal Perspective, Abstract. Twelfth Meeting of the UN Open-Ended Informal Consultative Process on Oceans and the Law of the Sea, New York, 20-24 June 2011, 1-4. http://www.un.org/Depts/los/consultative_process/ICP12_Presentations/Scovazzi_ Abstract.pdf

[31] International Seabed Authority (2013) Marine Scientific Research. http://www.isa.org.jm/en/scientific

[32] Lodge, M.W. (2012) The Common Heritage of Mankind. The International Journal of Marine and Coastal Law, 27, 733-742.

https://doi.org/10.1163/15718085-12341248 